\title{
CONDENSATION EXPERIMENTS OF MG-SILICATE MINERALS
}

\author{
A. TSUCHIYAMA \\ Institute of Earth and Planetary Sciences \\ College of General Education \\ Osaka University \\ Toyonaka 560 \\ Japan
}

\begin{abstract}
Condensation experiments were performed in the simple but most fundamental system $\mathrm{Mg}-\mathrm{Si}-\mathrm{O}-\mathrm{H}$ with forsterite vaporization source. At temperatures above about $1000^{\circ} \mathrm{C}$, euhedral crystals of forsterite $\left(\mathrm{Mg}_{2} \mathrm{SiO}_{4}\right)$ of a few $\mu \mathrm{m}$ were formed. These crystals are similar to olivines in Allende matrix. At temperatures below about $1000^{\circ} \mathrm{C}$, whiskers of forsterite and enstatite $\left(\mathrm{MgSiO}_{3}\right)$ were formed by vapor-1iquid-solid growth mechanism. These whiskers are different from enstatite whiskers in interplanetary dust, which were probably formed at small super coolings.
\end{abstract}

\section{INTRODUCTION}

Condensation is the most essential process for producing solid grains in the solar nebula and circumstellar regions. Many condensation experiments have been done for studying condensation processes in circumstellar regions (e.g., Nuth and Donn, 1982; Koike and Tsuchiyama, 1991), but important silicate minerals, such as olivine and pyroxene, have not been formed. On the other hand, only a few experiments appropriate to condensation in the nebula were done (Nagahara et al., 1988; Tsuchiyama et al., 1988). In these experiments, some important silicate minerals were formed, but the total pressure was too low compared to conditions in the nebula.

In the present study, condensation experiments were carried out in the simple but most fundamental system of $\mathrm{Mg}-\mathrm{Si}-\mathrm{O}-\mathrm{H}$ to obtain $\mathrm{Mg}-$ silicate minerals under conditions near those expected in the primordial solar nebula. Condensation products are compared with natural condensates.

\section{EXPERIMENTS}

Experiments were done with the condensation furnace described by Tsuchiyama (1989) (Fig.1). Powders of forsterite $\left(\mathrm{Mg}_{2} \mathrm{SiO}_{4}\right)$ placed at the bottom of the crucible were vaporized at $1480-1545^{\circ} \mathrm{C}$ for $15-90 \mathrm{hrs}$,

A.C. Levasseur-Regourd and H. Hasegawa (eds.), Origin and Evolution of Interplanetary Dust, 83-86.

- 1991 Kluwer Academic Publishers, Printed in Japan. 
and condensation took place from the gas on a cold finger with a temperature gradient from $1455^{\circ} \mathrm{C}$ to room temperature. A constant $\mathrm{H}_{2}$ pressure of $1.4 \mathrm{~Pa}$, which is similar to the nebula pressures, was obtained by bleeding of $\mathrm{H}_{2}$ gas into the chamber during evacuation. Redox conditions were controlled by the material of the crucible; a reduced condition near the $\mathrm{Ta}-\mathrm{Ta}_{2} \mathrm{O}_{5}$ buffer and neutral condition were obtained by the $\mathrm{Ta}$ and Mo crucibles, respectively. The ratio of $\mathrm{Si} / \mathrm{H}$ was about $10^{-2}$, which is larger than that in the nebula $\left(4 \times 10^{-5}\right)$. About $500 \mathrm{mg}$ or more of condensates were recovered as a function of the redox condition and temperature.

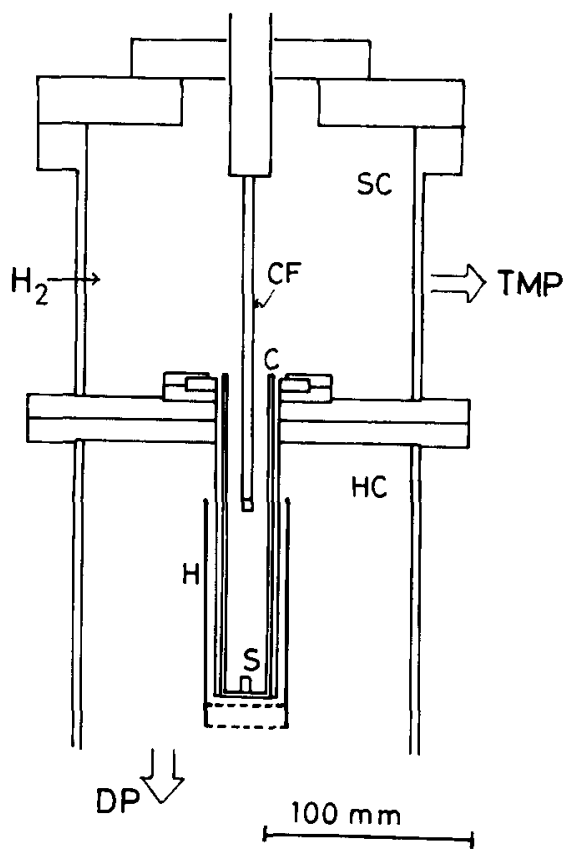

Fig. 1. A schematic drawing of the condensation furnace used in the present experiments. $\mathrm{SC}=$ sample chamber, $\mathrm{HC}=$ heater chamber, $\mathrm{CF}=$ cold finger $(\mathrm{Mo}), \mathrm{C}=$ crucible $(\mathrm{Ta}$ or $\mathrm{Mo}), \mathrm{H}=$ heater, $\mathrm{S}=$ vaporization source (forsterite).

\section{RESULTS}

Forsterite starts to condense at about $1200^{\circ} \mathrm{C}$ joined by silicon crystals at about $950^{\circ} \mathrm{C}$ in the $\mathrm{Ta}$ crucible, while forsterite at about $1200-1250^{\circ} \mathrm{C}$ jointed by enstatite $\left(\mathrm{MgSiO}_{3}\right)$ at about $900^{\circ} \mathrm{C}$ in the Mo crucible. In both experiments, condensates become amorphous at about $500^{\circ} \mathrm{C}$. The condensation sequences are qualitatively explained by thermochemical calculations of solid-gas equilibria (Tsuchiyama, 1989).

At high temperatures $\left(1250-1000^{\circ} \mathrm{C}\right)$ forsterite condenses as euhedral 
crystals usually elongated in the c-axis direction (Fig.2). At lower temperatures $\left(<1000^{\circ} \mathrm{C}\right)$ forsterite and enstatite condense as whiskers which always have amorphous droplets on their tops (Fig.3). The enstatite whiskers are clinoenstatite elongated to the c-axis direction.

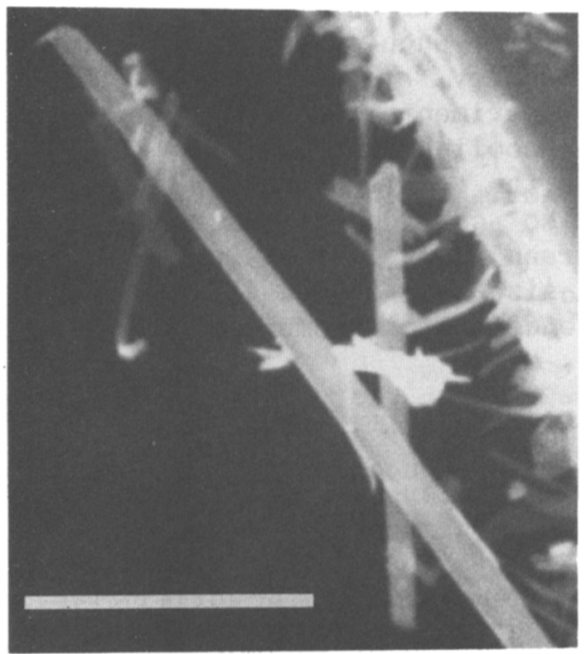

Fig. 2. A scanning electron micrograph of euhedral forsterite condensed at about $1120^{\circ} \mathrm{C}$ in the crucible. Scale bar is $10 \mu \mathrm{m}$.

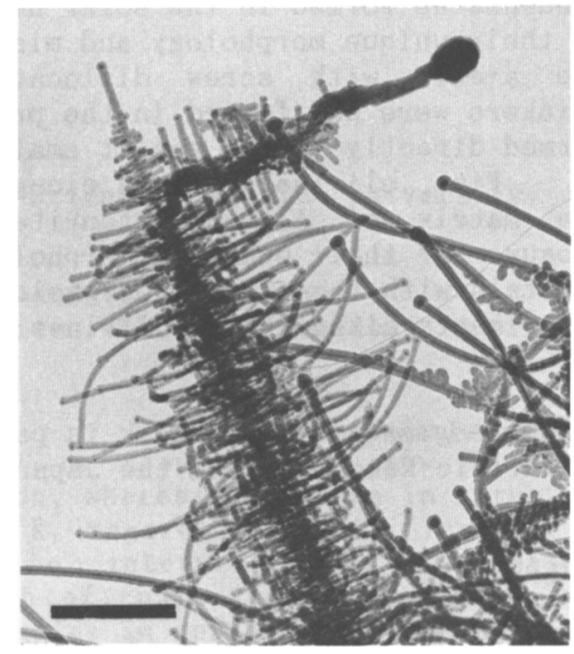

Fig. 3. A transmission electron micrograph of forsterite whiskers condensed at about $850^{\circ} \mathrm{C}$. Each $\mathrm{Ta}$ whisker always has an amorphous droplet on its top. Scale bar is $1 \mathrm{~mm}$.

\section{DISCUSSION}

\section{4-1. VLS growth mechanism of whiskers}

The amorphous droplets of the whiskers must be melted during the experiments. Thus, the formation of the whiskers can be explained as follows; (1) the melt droplets condensed first as a metastable phase, and (2) gas molecules are incorporated into the melt, and then forsterite, a stable phase, grows from the melts as whiskers. This is a kind of vapor-liquid-solid (VLS) growth mechanism (Wagner and Ellis, 1965). The metastable condensation of the melt can be explained by condensation at low temperatures with large super coolings.

It was pointed out that chondrules were formed by direct condensation of metastable melts in the cooling nebula (Blander and Katz, 1967). However, the present experiments indicate that direct condensation of melts would produce VLS-grown whiskers instead of chondrules. Such whiskers could be formed under large super coolings in dense parts of the primordial solar nebula although the VLS-grown 
whiskers have not been found in natural samples at present.

4-2. Comparison with natural condensates

Clinoenstatite whiskers in interplanetary dust are considered to be condensates formed in the solar nebula or presolar environments because of their unique morphology and microstructure, such as elongation along the a-axis with screw dislocations (Bradley et al., 1983). These whiskers were not formed in the present experiments. Probably, they were formed directly from a gas at small super coolings.

Fine olivine crystals elongated to the c-axis direction found in the matrix of Allende meteorite are also considered as condensates because of their euhedral morphology (Green et al., 1971). Forsterite crystals with the similar morphology and size were formed in the present experiments although the olivines in Allende contain some iron.

Acknowledgements. This work is partly supported by a Grant-in-Aid for Scientific Research from the Japan Ministry of Education.

\section{REFERENCES}

Blander, M. and Katz, J. L. (1967) 'Condensation of primordial dust' Geochim. Cosmochim. Acta 31, 1025-1034.

Bradley, J. P., Brownlee, D. E. and Veblen, D.R. (1983) 'Pyroxene whiskers and platelets in interplanetary dust: evidence of vapor phase growth', Nature 301, 473-477.

Green, H. W., Radcliffe, S. V. and Heuer, A. H. (1971) 'Allende meteorites: A high voltage electron petrographic study' Nature 172, 936-939.

Koike, C. and Tsuchiyama, A. (1991) 'The infrared spectra of synthesized amorphous silicates of olivine and pyroxene', this volume.

Nagahara H., Kushiro, I., Mysen, B. O. and Mori, H. (1988) 'Experimental vaporization and condensation of olivine solid solution', Nature, $331,516-518$.

Nuth, J. A. and Donn, B. (1982) 'Experimental studies of the vapor phase nucleation of refractory compounds. I. The condensation of SiO', Jour. Chem. Phys. 77, 2639-2646.

Tsuchiyama, A. (1989) 'Condensation experiments in the system $\mathrm{Mg}-\mathrm{Si}-\mathrm{O}-\mathrm{H}$ ' Lunar Planet. Sci. XX, 1136-1137.

Tsuchiyama A., Kushiro, I., Mysen, B. 0. and Morimoto, N. (1988) 'An electron microscopy of gas condensates in the system $\mathrm{Mg}-\mathrm{Si}-\mathrm{O}-\mathrm{H}$ ' Proc. NIPR Sym. Antarct. Meteorites 1, 185-196.

Wagner, R. S. and Ellis, W. C. (1965) 'The vapor-liquid-solid mechanism of crystal growth and its application to silicon', Trans. Met. Soc. AIME 223, 1053-1064. 